\title{
Corresponsalías de guerra españolas: un reflejo actual del periodismo internacional
}

\section{Spanish War Correspondent Offices: an Actual Reflection of International Journalism}

\author{
Eva Lavín de las Heras. Universidad Camilo José Cela (elavin@ucjc.edu) \\ Max Römer Pieretti. Universidad Camilo José Cela (mwalter@ucjc.edu)
}

Recibido: 10-II-2015 - Aceptado: 24-VI-2015

Resumen:

La evolución tecnológica con la aparición de Internet y las redes sociales, la crisis y otros factores, han provocado un nuevo cambio en la cobertura periodística de conflictos en particular y en la información internacional en general. Para tener una aproximación al problema de las transformaciones periodísticas que ha propugnado la aparición de Internet, se ha realizado un trabajo de campo que recopila 15 entrevistas en profundidad a corresponsales de guerra españoles. Este método de investigación cualitativa con su posterior análisis de contenido a los textos completos de las entrevistas, junto a una vista confluente entre los medios de comunicación y la relación de estos con las audiencias y la economía de la información, deja en evidencia que el trabajo periodístico de estos profesionales tiene cada vez tiene menos valor para los propios medios de comunicación que confían este tipo de información a la realizada por los freelances o las agencias de noticias.

Palabras clave:

Información internacional; corresponsal de guerra; freelance; Internet; redes sociales.

\section{Abstract:}

The technological evolution along with the appearance of Internet and social networking sites, the recession and other factors has brought about a change, particularly in coverage of war but also in the coverage of international news in general. In order to try to grasp this problematic journalistic transformation, caused by the appearance of Internet, we have carried out ground research consisting of 15 exhaustive interviews with Spanish war correspondents. Our qualitative research method and ensuing detailed analysis of the interviews was combined with a confluent look at the media and its relationship with it's audiences, as well as at the information economy in general. Our research clearly shows that a war correspondent's work is losing value for the media since they are turning to either freelance journalists or news agencies for this type of information.

Keywords:

International Information; War Correspondent; Freelance; Internet; Social Network. 


\section{Introducción}

El periodismo nació poco después de que apareciera una de las primeras y fundamentales herramientas para la difusión de mensajes: la imprenta. Desde entonces, este siempre ha vivido asociado a la tecnología; cada avance técnico ha traído consigo nuevos paradigmas informativos (García de Diego et al., 2007). Cada nuevo invento trajo como consecuencia una nueva forma de consumo de la información: el cine, la radio, la televisión han sido medios que han aportado a la labor periodística nuevas estructuras y lenguajes, no siendo Internet ajeno de esta realidad.

La popularización de Internet en los años 90 del siglo XX, dio origen a una nueva prensa, con su propia identidad, lenguaje y un rápido crecimiento que desafiaba a sus competidores. El miedo a perder lectores en beneficio de las páginas digitales informativas se convirtió en la rutina de los periódicos, y, más tarde, de los medios audiovisuales. El interés de los ciudadanos por conocer lo que ocurría en cada momento, fomentó la expansión de estos medios, que pronto encontraron vías comerciales, gracias a la publicidad y venta, prioritariamente, que establecerían un modelo de negocio que les permitió su desarrollo (López, 2010).

El periodismo sufrió una transformación radical, la mayor desde la creación de la prensa a penique a mediados del siglo XIX. En los inicios del XXI está surgiendo "una nueva forma de periodismo, con características como las noticias omnipresentes, el acceso global a la información, la cobertura instantánea, la interactividad, los contenidos multimedia y la extrema personalización del contenido" (Pavlik, 2005: 13-14). Según Pavlik, esto puede hacer que se recupere a un público distanciado pero a su vez, proyecta amenazas como "la autenticidad de los contenidos, la comprobación de las fuentes, la fidelidad y la veracidad están todas bajo sospecha en un medio donde cualquiera que tenga un ordenador y un módem puede convertirse en un editor global" (Pavlik, 2005: 13-14). Los nuevos medios provocan una redefinición de las relaciones entre las empresas informativas, los periodistas y sus diversos destinatarios, que comprenden a audiencias, fuentes, competidores, publicitarios y gobiernos (Pavlik, 2005).

Tuvo su punto de inflexión con las redes sociales (blogs, Facebook, Twitter, Flickr, etc.), que mostraron el interés de los ciudadanos por participar activamente en la elaboración de los contenidos informativos (Salvat y Paniagua, 2007). En la actualidad, la información ya no fluye de forma unidireccional, por ello algunos medios ya se han adelantado y han creado herramientas para fomentar la participación ciudadana y obtener así testimonios e imágenes inmediatas a coste cero (Lavín, 2014). Esto no sólo ha afectado al periodismo en general, sino a la información internacional y la cobertura de conflictos en particular. Es habitual ver en las televisiones o en la prensa escrita española, imágenes de conflictos que no han sido captadas por corresponsales o periodistas profesionales. Pero además otros factores han hecho que este tipo de información vaya perdiendo peso a lo largo de los años. Por eso consideramos fundamental, evaluar el estado de la situación, entrevistando a quince corresponsales de guerra españoles que en la actualidad siguen cubriendo la información inter- 
nacional pero ya algunos desde la redacción de sus medios. Por ello, nuestro objetivo será despejar la incógnita: ¿cuál es la situación de las corresponsalías de guerra y la información internacional dentro de los medios en España?

\section{Metodología}

Para analizar cuál es la situación de las corresponsalías de guerra y de la información internacional en la actualidad en los medios de comunicación españoles, se ha escogido como método de recolección de datos la entrevista en profundidad. Este método cualitativo se adopta por permitir bajo un guion de preguntas, ahondar en los temas objeto de esta investigación: conocer las alteraciones que la tecnología digital ha aportado a la recolección, producción y difusión de la información de conflictos internacionales, así como para el tratamiento de la información internacional.

Para la selección de la muestra, se consideraron los siguientes criterios categoriales:

- Han trabajado para un medio español de cobertura nacional.

- Han cubierto más de 5 conflictos.

- Han ejercido más de 8 años la profesión de corresponsal de guerra.

- Han trabajado más de 5 años realizando información internacional.

De esa forma se obtuvo una muestra de 15 periodistas, que a la vez, abarcan el espectro de las corresponsalías de guerra y la información internacional en todas sus ramas y diferentes medios prensa, radio, televisión, fotografía, prensa digital; así como diferentes generaciones.

Producto de esa selección, la tabla 1 expone la muestra de profesionales de la información a los que se entrevistó en profundidad desde mediados de 2012 a principios de 2014. 
Tabla1: Corresponsales entrevistados

\begin{tabular}{|c|c|c|c|}
\hline Nombre & Año de nacimiento & Tipo de medio & Nombre del medio \\
\hline Alfonso Armada & 1958 & Prensa & $A B C$, fronterad.com \\
\hline Ángeles Espinosa & 1962 & Prensa & El País \\
\hline Enric González & 1959 & Prensa & El País \\
\hline Guillermo Altares & 1968 & Prensa & El País \\
\hline Javier Espinosa & 1964 & Prensa & Época y El Mundo \\
\hline Alfonso Rojo & 1951 & Prensa & Diario 16, El Mundo y Periodista Digital \\
\hline Tomás Alcoverro & 1940 & Prensa & La Vanguardia \\
\hline Mónica G. Prieto & 1974 & Prensa digital & $\begin{array}{c}\text { El Mundo, Periodismo Humano y Cuarto } \\
\text { Poder }\end{array}$ \\
\hline Fran Sevilla & 1959 & Radio & RNE \\
\hline José Miguel Azpiroz & 1966 & Radio & Onda Cero y Punto Radio \\
\hline Vicente Romero & 1947 & Televisión & TVE \\
\hline Javier Mellado & 1957 & Televisión & El Mundo y Antena 3 \\
\hline Gervasio Sánchez & 1959 & Fotoperiodista & $\begin{array}{l}\text { Cadena SER, El Heraldo de Aragón y La Van- } \\
\text { guardia }\end{array}$ \\
\hline Antonio Pampliega & 1982 & Freelance & $\begin{array}{c}\text { La Sexta noticias, Público y agencia France } \\
\text { Press }\end{array}$ \\
\hline Alfonso Bauluz & 1965 & Agencia de noticias & Agencia EFE \\
\hline
\end{tabular}

Fuente: Elaboración propia

También nos hemos apoyado en bibliografía y artículos de prensa en los que otros profesionales hablan directamente de la problemática.

\subsection{El guion de entrevista}

Estuvo fundamentado en varias partes. La primera, sobre las características del corresponsal en un conflicto armado, vivencias, medios tecnológicos usados, dificultades para realizar el trabajo, transformación de la tecnología a lo largo de su vida profesional. La segunda parte de la entrevista versa sobre la relación del profesional de la información con sus medios de comunicación, como freelance o con su agencia de noticias, el uso de Internet por parte de los medios de comunicación tradicionales, la saturación de la información o manejo de la misma por parte del lector. 


\section{Resultados}

La crisis, la competencia con Internet y los problemas económicos de los medios de comunicación, cada vez menos dispuestos a invertir dinero en coberturas tan costosas como las que realizan los corresponsales de guerra ha provocado un cambio en las coberturas de conflictos pero también en la información internacional. Por ello, vamos a analizar los diferentes factores sobre los que ha incidido:

\subsection{Situación de las corresponsalías de guerra y la información internacional}

La información internacional ha perdido peso en los medios de comunicación, ya lo dijo el magnate de la prensa mundial, Rupert Murdoch, "la información internacional no vende" (Fernández y Marcos, 2009: 90). El hecho de que la información internacional sea más cara que otro tipo de cobertura por la necesidad de desplazar a un equipo, añade un extra negativo al objetivo comercial y deja claro que estas noticias no conllevan beneficios económicos a priori (Fernández y Marcos, 2009). Algo que se agudiza con la cobertura de un conflicto en el que además hay que incluir otros costes como el de la seguridad.

José Miguel Azpiroz, excorresponsal de la cadena de radio, Onda Cero, tiene claro que "el periodismo agoniza porque prima el negocio sobre la responsabilidad social" (2013), algo que apoya su colega, Fran Sevilla, corresponsal de RNE: "cada día más, los medios en las guerras, se rigen por el mercantilismo, lo que buscan es una rentabilidad económica, no una rentabilidad social. Cubrir una guerra es muy cara y los medios ya no apuestan" (2013). El fotoperiodista, Gervasio Sánchez considera que la información internacional sí que interesa y que "es un problema económico, un minuto de internacional cuesta 10 veces más que cualquier otra cosa. Al ser tan caro, dicen que no merece la pena, pero ha pasado toda la vida. Antes era 'estamos ganando menos' pero ahora es 'estamos perdiendo más' ” (2013).

A Kapuściński esta situación le parecía paradójica, consideraba que el desarrollo de las comunicaciones había conectado prácticamente todos los puntos del planeta, convirtiéndolo en una aldea global, mientras que, por otro lado, la temática internacional ocupaba cada vez menos espacio en los informativos, desplazada por la información local, las noticias sensacionalistas o por los chismes. Considera que la civilización todavía no está preparada para combatir "la manipulación, la corrupción, la arrogancia y la veneración de la porquería" (2001: 402).

Para Rosa María Calaf, excorresponsal de TVE, uno de los males que afecta al periodismo es la idea de que "no interesa lo que pasa lejos, como si no fuera con nosotros” (2008: 99). Según ella, a los medios les interesa más la banalidad de otros temas, y pone como ejemplo estudios realizados en Estados Unidos que indican que la información sobre temas internacionales está disminuyendo de forma alarmante. "Por ejemplo, en el 2005, (...) al genocidio en Darfur, en Sudán la CBS dedicó tres minutos; la NBC dedicó cinco minutos, todo esto en un año o que la muerte de la llamada modelo Anne Ni- 
cole Smith y la pelea por saber quién era el padre de su hija ocupó diez veces mayor espacio en la televisión que la guerra de Irak" (2008: 99). Y añade: "el director de la revista Newsweek ha dicho que poner una portada de internacional, salvo que sea algo muy turbador, baja las ventas en kiosco un 25\%” (Calaf, 2008: 101).

Pero esto también pasa en España, en donde cada vez las piezas en los informativos de televisión son más cortas: "Cuando me fui hace 23 años a EE.UU. hacía piezas para el telediario de tres minutos; cuando abrí la oficina en la Unión Soviética, cuatro años después, eran de dos minutos y medio, minuto y cuarenta segundos; ahora, si tienes un minuto y diez te das con un canto en los dientes. Las crónicas cada vez son más superficiales y cada vez son más titulares. Y eso está convirtiendo a los periodistas en simples lectores de comunicados de prensa" (Calaf, 2008: 102).

El periodista británico, Russell Miller (2001)cree que todo comenzó al principio de los años noventa, con el nacimiento del periodismo centrado en las celebridades. El éxito de las revistas como L'copie o el VanityFair llevó a los directores a cuestionar la relevancia comercial, y hasta moral, del fotoperiodismo, poniendo más énfasis a las entrevistas con los ricos y famosos que a los fotoreportajes. Carl Bernstein, periodista del Washington Post que junto con Bob Woodward, destapó el escándalo Watergate, también está de acuerdo: “[El periodismo] está desfigurado por los famosos, los chismes y el sensacionalismo. Creo que el papel de los periodistas es plantear retos a la gente, no sólo de divertirles con tonterías. En esta cultura del cotilleo periodístico, les estamos enseñando a nuestro lectores y espectadores que lo trivial es importante" (Pavlik, 2005: 52-53).

En España, también los corresponsales tienen esta opinión, como explica Javier Mellado, excorresponsal de Antena 3: "Estamos en un momento en el que ves que Siria hoy no ocupe ni el 0,1\% en ningún informativo y la selección española de futbol a lo mejor ocupa un 80\%. El 20 de marzo del 2003, cuando se inicia la guerra de Irak nosotros estuvimos 24 horas emitiendo, todo el mundo hizo un despliegue importante, pero el programa más visto fue Hotel Glamour de Telecinco. Se está perdiendo el foco de las cosas importantes, toda esta proliferación de información lo que hace es enmarañar y no deja profundizar" (2012).

Otro corresponsal muy crítico es Javier Espinosa, del periódico El Mundo, considera que sólo los medios que hagan periodismo intelectual serán los que sobrevivirán a la crisis, porque habrá gente dispuesta a pagar por leerlos: “Si pones en el título la palabra sexo o escándalo tendrás dos millones de visitas. Si pones la palabra Siria, tan sólo 50. Pero yo leo a diario los artículos de Jon Lee Anderson en The New Yorker y pagaría por ello" (2013).

El que fuera corresponsal de $A B C$, Alfonso Armada, al igual que Miller, piensa que esta tendencia empezó en Estados Unidos y afirma que "el despliegue gráfico que se dedica a acontecimientos internacionales también ha disminuido mucho" (2013). Además Gervasio Sánchez explica otro hecho: "antes no se publicaba una foto mala y hoy en día sí, ha bajado muchísimo la calidad. Técnicamente han mejorado porque las cámaras digitales te enfocan solas, no hace falta preocuparte 
por la luz... pero otra cosa es la calidad de imagen (...). La calidad está cayendo porque se invierte menos en periodismo" (2013). Diego Caballo, fotoperiodista de la Agencia EFE, apunta a que "hay que ser capaces de concienciar a los medios de que no se trata de rellenar páginas, sino de ofrecer calidad” (Varela, 2013).

Alfonso Armada nos habla también de un nuevo efecto aparecido con el periodismo digital, que es la obsesión por la audiencia: "Ahora la obsesión por el tráfico en Internet es lo que manda. Cada día se publican las noticias más visitadas y, la mayoría de ellas, son auténticas estupideces si el baremo es ese, creo que estamos perdidos. Los temas sociales o de cotilleo han invadido todo, incluyendo periódicos serios que cada vez les dan más espacio porque creen que eso atrae lectores, creo que es una zona muy peligrosa y nos deslizados hacia la irrelevancia" (2013).

En la segunda mitad del siglo XX, especialmente los últimos años, tras el fin de la guerra fría, con la revolución de la electrónica y de la comunicación, según Kapuściński (2002), el mundo de los negocios descubrió que la verdad y la lucha política no eran importantes, sino que lo que contaba, en la información, era el espectáculo. Por eso se crea la información-espectáculo y advierte que nos encontramos en una era de la información completamente distinta, en la que la información es una mercancía que dejó de estar supeditada a los criterios tradicionales de la autenticidad y la falsedad, estando ahora sujeta a las leyes del mercado: conseguir una rentabilidad máxima y mantener el monopolio. Y afirma que "el valor de la información se mide por el interés que puede despertar. Lo más importante es que la información pueda ser vendida. Por verdadera que sea una información, carecerá de valor alguno si no está en condiciones de interesar al público, por otro lado cada vez más caprichoso" (Kapuściński, 2001: 394).

Calaf apoya esta teoría sobre el info-entretenimiento, en las que los medios buscan consumidores "a los que hay mucho que vender y a los que no hay por qué contar demasiado" (2008: 99). Alfonso Armada apunta que la competencia es tan grande que hace que los medios entren en el juego "hay que tener cuidado ahí porque introduces elementos que no son propios de la información sino del espectáculo” (2013).

Dentro de este info-entretenimiento aparecería la mitificación de los corresponsales de guerra. En ella los propios informadores se convierten en protagonistas, como narra Gervasio Sánchez: "uno de los vicios mayores de la prensa española es que la gente, sobre todo joven, habla más de lo que les pasa a ellos que de lo que pasa, de la realidad de la guerra. Cada vez que utilizas un espacio para hablar de lo que te pasa a ti lo haces pisoteando el espacio que debería estar dedicado a la única verdad incuestionable de las guerras: las víctimas civiles (...). Para mí el periodismo es compromiso” (2013).

\subsection{Ahorro en costes}

El ahorro en los costes es sin duda otro de los puntos más significativos. A pesar de que la evolución tecnológica ha provocado un descenso en los gastos, los corresponsales han pasado de usar caros sistemas de transmisión, a poder mandar 
sus crónicas, fotografías o imágenes a través de un correo electrónico o Internet, los medios cada vez mandan menos a un corresponsal a cubrir un conflicto.

Cuando los medios mandan a un corresponsal a un conflicto, uno de sus intereses es mostrar su presencia, lo que muchas veces es un inconveniente porque obliga al reportero estar constantemente en directo o actualizando las informaciones. Algo que Javier Mellado, considera que perjudica a su trabajo: "Dejar de hacer cosas porque tienes que estar saliendo cada minuto es contraproducente. Eso no es periodismo. Si tengo que entrar en directo, me están impidiendo hacer mi trabajo" (2012).

Pero para Enric González, corresponsal del periódico de El País, el hecho de que un corresponsal esté en directo en todo momento, considera que simplifica su trabajo pero con una evidente pérdida de calidad: "por un lado se le explota más, pero por otro lado se le pide algo que es mucho más fácil, que es la presencia. Se le pide que se conecte y que cuente esto, algo que ya sabes porque te han dado paso diciendo, ¿a que pasa esto? Eso es una estupidez porque es el trabajo más fácil del mundo y no sé qué servicio proporciona al ciudadano. Si no te dejan hacer el trabajo profundo, todo eso que te ahorras, estar diciendo estupideces durante 14 horas, en esa jornada, y la empresa se queda muy contenta porque se cree que eso vale para algo y así les va a las empresas" (2014).

Los reporteros ahora cuentan con herramientas que les permite enviar una crónica desde un ordenador portátil, hacer actualizaciones en un blog, filmar una entrevista, tomar fotos, grabar audio, editar un vídeo y colgarlo directamente en la web del medio, un trabajo que antes hacían tres personas pero como explica Bárbara Celis (2008), el periodista ya no ocupa ese lugar privilegiado que ha tenido durante siglos en la cadena y si no se adapta a los cambios, no tendrá cabida. Los periodistas ya no controlan en exclusiva el contenido y el formato de las noticias.

Cuando un grupo audiovisual manda a un periodista a cubrir un conflicto, le pide que trabaje también para los otros medios, reduciendo así los gastos. Fran Sevilla nos lo explica: "ahora el mismo redactor hace radio, tele, etc. Radio es un medio específico, hay que saber hablar, la voz, la entonación y a veces escuchas a muchos colegas que no son del medio radiofónico y es horroroso, pero se emite. Hay gente que puede hacer radio, pero no sabe escribir bien el texto, en televisión, igual" (2013).

Otra tendencia de los medios para recortar el coste de las coberturas es reducir el equipo que viaja, habitualmente viajaba el redactor, el cámara, un ayudante de cámara y el productor, pero con los equipos más ligeros, se eliminó la figura del ayudante y ahora la del productor no es tan habitual. Alfonso Bauluz, excorresponsal de la Agencia EFE, explica su experiencia en 1991 durante la guerra del Gofo: "Yo hacía televisión, radio y texto. No hacía foto. Pero yo viajé con un cámara y una chica de producción, pero, como redactor, hacía el reportaje para las autonómicas, los textos para la agencia y entraba en la radio. Hay gente que es polivalente y gente que no" (2013). 
Pero esto ya pasaba, según Alfonso Rojo (2013) siempre era a él, al que mandaban a cubrir los conflictos porque además de escribir el texto, podría hacer también las fotos por el mismo precio. Algo que sigue pasando en la actualidad y sobre lo que aporta luz Javier Espinosa: "Si no planteas límites te hacen hacer de hombre orquesta. Hay mucha gente que yo conozco que les obligan a hacer vídeos, texto, Internet, dos artículos sobre lo mismo. Eso es imposible. Cuando yo empecé era fotógrafo y redactor y lo dejé porque era imposible. Era muy mal fotógrafo y decidí que lo hacía un poco mejor escribiendo, y me pasé a la redacción porque las dos cosas no me salen bien (...).Y por esto la gente no paga, porque lo tienes en Internet gratis" (2013).

Mónica G. Prieto a esta polivalencia la denomina "periodista orquesta": "es absurdo, es un modelo que ha aplicado los medios convencionales cuando apareció Internet, eso de que el periodista tenía que hacer todo. La figura del cámara o del fotógrafo es fundamental y eso afecta a la calidad del producto y, por tanto, a la credibilidad del medio" (2013).

La realidad es que la tecnología ha provocado un cambio en el que nos encontramos inmersos, a pesar del ahorro en los gastos de transmisión, las coberturas de conflictos están disminuyendo, por ello, cuando un periodista viaja, se le pide un mayor rendimiento para economizar esos costes. Guillermo Altares, excorresponsal y director de la sección de información internacional del periódico El País, aventura una posible fórmula de convivencia: "Los periodistas que actualmente se dedican a la información internacional, tendrán que ser capaces de encontrar un equilibrio entre las exigencias que plantean los nuevos medios, la presencia constante, la esclavitud de la actualización (...) con la base del oficio: contar algo que los demás no tienen, buscar la diferencia. Y esa búsqueda requiere un tiempo y un espacio" (Altares, 2010: 41-42).

\subsection{Freelance}

La contratación de corresponsales freelance empieza a ser una fórmula habitual para la mayor parte de los medios y agencias a la hora de cubrir un conflicto. La principal razón es la económica, pagan sólo por el material que les interesa, ahorrándose todos los gastos de viaje, alojamiento y dietas, el seguro, comunicaciones e imprevistos que puedan surgir. Tomás Alcoverro, nos cuenta que él lo ha padecido: "en las últimas elecciones del Cairo no he ido yo, como siempre he ido. Han contratado un freelance al que pagan 100 euros por la crónica” (2013).

Estas son algunas de las causas por las que proliferan los freelance, profesión que José Miguel Azpiroz valora “tiene un mérito enorme. Además de las dificultades que tienen todos, ellos no tienen el respaldo de un gran medio, el dinero o los contactos entre otras cosas" (2013). Por otra parte, Javier Mellado considera que "hay gente que no está preparada porque es su primer conflicto, se lo juega a todo o nada, que no tiene capacidad muchas veces económica para alquilarse un coche con un buen traductor o un chofer-traductor que realmente le pueda ayudar a moverse. Hay que estar allí pero sabiendo dónde estás" (2012). 
Pero Alfonso Armada considera que esta figura degrada la vida de corresponsal y nos narra su experiencia personal: "Las empresas argumentan que la situación económica no permite otras cosas. Desde el punto de vista laboral las cosas están mucho más duras, les pagan mucho menos y tienen menos respaldo jurídico, político y económico. Es una tendencia imparable" (2013).

En junio del 2011, el diario $A B C$ empezó a negociar el despido de cinco de sus siete corresponsales porque la empresa consideraba que no podía mantener ese gasto (Redacción Prnoticias, 2011). Javier Espinosa también hace referencia a este caso al hablar de esta figura: "Es un debate que hay ahora mismo, hay dos tendencias, una de medios de comunicación que han suprimido a los corresponsales de plantilla, como el diario $A B C$, dejando a los freelance. Mi opinión personal es que el valor añadido de una persona que vaya al lugar de los hechos y que te informe con respecto a un ciudadano ' $x$ ' que no tiene formación de periodista no es comparativo. (...). Ahora se han bajado los baremos de lo que es aceptable en periodismo por la crisis, porque no importa, hay muchos factores. Pero la figura del corresponsal sigue siendo necesaria" (2013).

Fran Sevilla critica esta situación pero no apunta a los profesionales sino hacia los medios: "Los medios van recortando costes, está claro que le sale más barato un freelance que un corresponsal, pero además la figura del corresponsal está de capa caída y desapareciendo (...). Mi crítica no es a los freelance sino a los medios (2013).

Antonio Pampliega, el único corresponsal freelance que hemos entrevistado, nos explica su situación: “Los 'free’ (...) nos vendemos al mejor postor al que no le importa el producto que tenemos, sino llenar páginas y páginas de información. Mal pagados, puteados y hartos de la indiferencia. Entre los que cubren los conflictos bélicos comienza a surgir la pregunta ies rentable seguir trabajando en zonas de conflicto? La respuesta aún no ha llegado, porque cada vez hay más free españoles trabajando sobre el terreno, pero solo a 1 de cada 10 les renta ir a las guerras" (2013).

La fotógrafa del National Geographic, Alexandra Avakian, afirma que "la profundidad cuesta dinero" y denuncia que, por todo un reportaje, las revistas pagan hoy lo que cuesta un hotel en el país donde se elabora o que intentan imponer tarifas planas para comprar imágenes (Cazorla, 2009). Pero a pesar de estos inconvenientes, Guillermo Altares, jefe de internacional de El País, cuenta que cada vez "hay más gente que me ofrece historias desde lugares muy remotos y con una facilidad de transmisión enorme" (2013).

Pero Juan Pedro Valentín, director de informativos, lo tiene claro: “Tener un periodista para cubrir un país entero es menos rentable que tener un acuerdo con una cadena nacional en ese país para que te suministre sus imágenes y noticias (...). Así vamos adelgazando las estructuras de nuevas redacciones en busca de esa eficacia que además conlleva una mayor rentabilidad. Rentabilidad y periodismo son dos conceptos que no se suelen llevar muy bien pero que la realidad se empeña en emparejarlos" (2007: 75). 
Una de las preocupaciones más acuciantes entre los propios corresponsales es la desaparición paulatina de los grandes testigos, como reflexiona Iñaki Gabilondo: "La investigación en profundidad quedará reducida a una tarea casi siempre de freelance, con dos trabajos complejísimos. Primero, ir a las zonas de conflicto a jugarse la vida. Y en segundo lugar, si cabe más difícil, tratar de colocar sus reportajes y sus crónicas en los medios de comunicación, [mal] acostumbrados a resolver la cobertura de noticias lejanas con cuatro imágenes de YouTube y un par de notas de agencia" (2011: 98).

\subsection{Agencias de noticias}

Las agencias de noticias mantienen en la actualidad su influencia sobre los medios siendo una de las principales fuentes de información. Alfonso Armada también considera que las agencias dan pistas sobre lo que puede estar pasando, "te da una visión más panorámica. (...). El problema es cuando no hay diálogo entre la redacción y el enviado especial y se fían más de la crónica de la agencia que de la tuya. Es verdad que la agencia está dónde tú no estás, de eso no hay duda" (2013).

Pero la falta de diálogo entre corresponsal y la redacción es bastante frecuente por lo que puede generar conflictos, como nos cuenta Javier Espinosa: "A mí me ha pasado mil veces, que Madrid te explique lo que está pasando en el sitio donde estás, que te digan 'es que lo ha dicho EFE'. Además, encima, la Agencia EFE que en mi región tiene una cobertura nefasta. Y te dicen 'hay que ir por aquí' y tú les dices que eso no es lo que estás viendo y lo que está pasando y te dicen 'pero es que EFE...'. El problema no son las agencias en sí mismas, sino la percepción de los jefes de las agencias y su prepotencia, de intentar interpretar lo que está pasando en el terreno según lo que dicen a las agencias, en vez de confiar en sus enviados especiales o corresponsales que son los que lo están viendo" (2013).

Pero Ramón Lobo cuenta una anécdota en su libro El héroe inexistente en el que también lo vivió en primera persona: "África no es Bosnia, donde cada agencia informativa disponía de varios redactores, entre extranjeros y locales, y obtenían una considerable ventaja de medios humanos sobre cualquiera de los demás. "Oye, Ramón: que Reuters dice que son ya dieciséis los muertos y no once como escribes en la crónica", te corregían por teléfono desde la redacción central; y tú te sentías obligado a agachar la cabeza y responder: "Si lo dice Reuters, es que es así” (1999: 254-255).

Lobo cuenta otro caso para explicar que esto no son casos aislados que ocurren sólo en nuestro país, también pasa en diarios de gran prestigio internacional: "En Zaire, el enviado especial del diario británico The Daily Telegraph, conservador y el primero en ventas en Reino Unido, le reescribieron la crónica desde Londres para comenzar por lo que consideraban lo más importante: 'Los rebeldes han tomado Kinshasa'. Nadie en esa santa casa tomó en consideración la posibilidad de llamar a su periodista por teléfono y contrastar la nueva información. Las agencias daban la noticia de manera escueta y esa resultaba una prueba irrefutable de la realidad" (Lobo, 1999: 254-255). 
Pero muchos apuntan a la profesionalidad de los jefes de internacional de muchos medios. Gervasio Sánchez explica que "cuando, hace veinte años, yo tenía veinte, los periodistas que tomaban las decisiones en las redacciones tenían cultura general, capacidad de decisión y asumían grandes riesgos. Me doblaban en edad y experiencia y uno respetaba la palabra y el consejo del redactor en jefe (...). Hoy, ya con más de cuarenta años, esos mismos puestos están ocupados por personas de mi misma edad que han renunciado a la crítica, se dejan arrastrar muy fácilmente por lo que les dan mascado las grandes agencias internacionales, y son incapaces de asumir riesgos, más preocupados por subir escalones en la jerarquía del medio que por hacer periodismo de verdad" (Sánchez, 2001: 468).

Amplía Lobo que un cronista en una guerra compite en desventaja contra dos imperios: las cadenas televisivas y las agencias internacionales de prensa. "La perversión no está tanto en su trabajo, meritorio casi siempre, sino en el efecto devastador que a veces ejerce sobre el tuyo" (Lobo, 1999: 179).

José Miguel Azpiroz, considera que las agencias "son una herramienta, pero no pueden convertirse en el núcleo de tus crónicas. El enviado especial tiene que contar lo que ve, no lo que ven otros periodistas, y nunca en primera persona. Viajas para contar lo que les pasa a otros, no a ti" (2013).

Pero al igual que los freelance o la información extraída de Internet, los medios de comunicación, muchas veces recurren a las agencias para suplir la carencia de corresponsales en una zona de conflicto. El principal motivo es el económico y, como dice Rosa María Calaf, "los documentados artículos sobre asuntos internacionales no son, en estos momentos, una prioridad. Y la consecuencia es que las empresas, en sus campañas por ahorrar, se inclinan por trabajar, cada vez más, con noticias de agencia o lo que hemos dado en llamar paracaidistas, es decir, periodistas que se desplazan puntual y esporádicamente para ocuparse de un tema. Cada vez más se prescinde de los especialistas en internacional y de los corresponsales" (Calaf, 2008: 101). Antonio Pampliega confirma que incluso prescinden de los corresponsales freelance: "con las agencias internacionales e Internet... Los medios han tenido la brillante idea de pensar que se puede informar de lo que ocurre en Somalia desde una oficina en Madrid. La información internacional ha pasado a un segundo o tercer plano... y con un breve o unas imágenes de cola se dan por satisfechos" (2013).

La escasa diversidad de fuentes es otro problema que sufre la información internacional en España. Los medios nacionales fundamentalmente se nutren de las noticias ofrecidas por las grandes agencias internacionales (Reuters, AP y AFP), además de la española EFE, limitando su visión a un par de fuentes. Problemas o deficiencias que se multiplican al considerar como elemento influyente en la información internacional el número de corresponsales o enviados especiales de los medios que sin duda es escaso y que tiende a desaparecer (Fernández y Marcos, 2009).

Para Rosa María Calaf, el trabajo que realiza un enviado especial de una agencia puede ser mucho más superficial que el que puede dar un corresponsal que vive en la zona: "Porque se llega, se informa y se marchan y con frecuencia se ofrece 
un tratamiento simplista e incompleto porque no hay nadie, primero, que pueda saber de todo; y segundo, que sea capaz de estar informando en la nieve en Navacerrada y la semana que viene estar en la guerra porque, evidentemente, no tiene tiempo de prepararse" (Calaf, 2008: 101).

Las agencias de noticias son consideradas en general por los corresponsales como una fuente de información que les ayuda en muchas ocasiones, dan una visión más panorámica sobre el conflicto, al contar con mayor número de periodistas en origen, consiguen llegar a puntos que muchas veces los corresponsales no pueden. El conflicto viene cuando las agencias son utilizadas en contra del corresponsal, y los jefes de los medios dan más valor a lo que publican que a la información que transmite su propio reportero. También en la actualidad muchas veces están supliendo la figura de corresponsal en un conflicto, porque al medio les sale más barato.

\subsection{Crisis}

La revolución electrónica ha provocado una multiplicación de medios, a los que ha acudido el gran capital y en el que la información se ha convertido en mercancía, como dijo Kapuściński, "los románticos buscadores de verdad que antes dirigían los medios fueron desplazados por hombres de negocio” (2001: 394). Nemesio Rodríguez, ex corresponsal de la Agencia EFE, confirma que estos solo accedieron al mundo de los medios de comunicación cuando se percataron que la información era una transacción y les acusa de ser “ajenos por tanto a nuestra profesión y sin interés hacia ella, han venido tomando medidas destinadas a limitar nuestro peso, a veces en convivencia con periodistas que han confundido su papel con el de los propietarios: cierran corresponsalías, promueven la figura del periodista orquesta, obligándonos a trabajar en todos los soportes posibles con el argumento de que 'el mercado lo exige' (2009: 14).

Pero Alfonso Armada tiene claro que uno de los mayores errores y origen de la crisis ocurrió porque los medios no fueron capaces de cambiar tecnológicamente cuando tenían rentabilidad suficiente para acometer las reformas: "Los medios deberían ser visionarios, pero no lo han sido. Y ahora con la llegada de Internet, los medios han cometido muchos errores también, regalando la información que vendían en los kioscos al mismo tiempo. Desde un punto de vista comercial es suicida y ahora estamos en un momento de perplejidad absoluta. Internet es una herramienta que está ahí, ha venido para quedarse y nos va a obligar a cambiar la forma de hacer y sobre todo de ganar dinero" (2013). Javier Espinosa (2013) está de acuerdo en que el mayor error fue dar en Internet la información gratis y considera que el gran reto es volver a hacer que la gente pague por la información.

Pero hay corresponsales como Rosa María Calaf que consideran que la crisis en el periodismo es una realidad, "se producen por igual programas de televisión que refrigeradores, proliferan los medios que sacrifican el rigor periodístico en aras de los índices de audiencia, los tribunales fallan contra los periodistas que defienden el secreto de sus fuentes, como ha sucedido recientemente en Estados Unidos, (...) la voz del periodista es cada vez más débil y, por ende, cada vez participa 
menos en el diseño de la información. La investigación periodística es un acto que se está convirtiendo en secundario. La crítica, el análisis, dos herramientas básicas del periodismo, están prácticamente en extinción” (2008: 98-99).

José Miguel Azpiroz es rotundo "la crisis ha terminado por matar al corresponsal, al enviado especial y al freelance" (2013) igual que Tomás Alcoverro que aclara: "el trabajo del corresponsal tiene dos grandes dificultades, la tecnológica y ahora la económica que ha venido después. Se encuentra que se tiene que adaptar a la información instantánea, además ahora a la falta de medios y esto puede ser una puntilla a la figura del corresponsal” (2013). Pero Enric González tiene claro el papel que tienen que jugar ahora, si quieren seguir siendo fieles a sí mismo y sus lectores: "tienes que conseguir ser lo bastante hábil como para trabajar para los tuyos, para el lector, sin que te despidan. Sin enfrentarte de una manera frontal con lo que es la realidad comercial y empresarial, que es primero la necesidad de sacar dinero -no me parece mal aunque a veces es de mal gusto-y sobre todo la necesidad de contentar a los intereses empresariales” (González, 2012).

Corresponsales como Javier Espinosa hacen balance y añoran tiempos pasados: "a nivel sentimental me parecía más bonito el trabajo del corresponsal en la época de Manu Leguineche en la que era más difícil acceder a la información y mucho más difícil transmitirla. Se valoraba más y era más aventura, interesante el trabajo en sí mismo” (2013). Aunque también considera que en la actualidad el trabajo es más fácil y que para el público es más beneficioso, porque hay más cantidad de información para analizar. José Miguel Azpiroz es bastante negativo con el futuro de la profesión: "a pesar de que en España ha habido y hay grandes profesionales, soy muy pesimista sobre el futuro de la profesión en general y el de la información internacional en particular" (2013).

Pero todos no tienen la misma opinión, periodistas como Gabilondo mantienen la esperanza de que "tal vez algún día alguien descubra el negocio del periodismo de verdad, porque ahora mismo todavía priman las razones económicas” (2011: 103).

\subsection{Situación de la información}

Pero todo esto no sólo ha afectado a las corresponsalías o al periodismo internacional, una de las consecuencias más inmediatas de esta eclosión tecnológica es el continuo fluir de datos, noticias y opiniones que ha afectado a los cimientos del periodismo en general.

Como detalla Alfonso Rojo (2013) "hemos pasado de la escasez a una abundancia de información. El bombardeo es excesivo". El ciudadano que vive en una sociedad moderna tiene a su disposición toda la información que puede desear, pero Alfonso Armada reflexiona "quizás también por este bombardeo informativo, hace que la gente en vez de estar mejor informada, esté más pérdida y creo que los medios están fallando en poner eso en contexto y explicarlo. Creo que hace falta más espacio y más espacio internacional”, y sigue “hay una saturación de información donde la información neta, está me- 
tida en una especie de montaña de escoria, de la que es difícil dilucidar lo que es valioso de lo que no e Internet ha propiciado esto de forma exponencial, con lo cual el grado de ruido que hay ahora es mucho más grande. Es mucho más difícil extraer las pepitas de oro de toda esta especie de masa que no vale para nada. Hay muchas más posibilidades de conseguir información pero hay a la vez muchísimo ruido con lo cual la sensación que tiene la gente, yo creo que es de saturación y de desinformación" (2013).

Otro escéptico es Joan Majó que señala que disponer de más información "no significa tener más conocimiento, y un exceso puede crear serios problemas tanto de selección y de ingestión cuanto más de digestión” (1997: 50-51). Muchos de los corresponsales, como Enric González, consideran que estamos peor informados "hay cantidad de datos, toneladas, un universo de datos flotando por ahí pero inconexos, es mejor un trabajo que te permita entender un poco lo que pasa que no tener cantidad de titulares que se olvidan en un segundo. Creo que la inmediatez tiende a la frivolización" (2014). Javier Mellado considera que la información "la utilizamos como consumo de usar y tirar, no se profundiza nada. Ahora la gente recibe mucha información y pueden pasar cosas importantísimas pero estamos ya como acostumbrados, no nos afectan ya. No estamos mejor informados, se ha perdido profundidad en la información y rigor” (2012).

Gervasio Sánchez también tiene dudas sobre si los cambios tecnológicos ha mejorado la calidad de la información: "tengo la sensación de que todo lo que se ve, se lee, se escucha es lo mismo. Todas hacen refrito. Es como los periódicos cada día, nacen con las portadas muertas, pero hoy lo que pasó ayer no es noticia. El periódico debería analizar, alguien que te cuente que ha pasado, que te contextualice, crónicas de testigo directo, eso hace factible la calidad periodística. Los medios repiten las mismas historias" (2013).

Vicente Romero considera que en la Red circula una cantidad de noticias "malinterpretadas, parcialmente ciertas y hoy es muy fácil manipular, ocultar, mentir, más de lo que ha sido nunca a pesar de la facilidad de inmediatez y de torrentes de comunicación" (2014).

Otro de los problemas es que actualmente nos llega información por diferentes medios, a parte de los tradicionales, disponemos de móviles, faxes, Internet, teléfonos, etc. Según Calaf (2008) se está creando una especie de muro de ruido, que está consiguiendo lo contrario de lo que se supone que debería conseguir, ya que no permite la reflexión, y esto hace que en la era de la información, sea cuando peor informados estamos. Kapuściński ya en el 2001 consideraba que "lo más difícil es disponer del tiempo necesario para poder asimilar toda la oferta existente" (2001: 408).

Alfonso Armada considera que los medios se están ocupando de ser prescindibles entre "la poca atención, falta de profesionalidad y la frivolidad con la que se acercan a la gente a la que si les interesa" (2013). Iñaki Gabilondo augura otro destino reflexionando sobre el futuro del periodismo: "Será periodismo será diferente, las estructuras no serán las mismas y cambiarán los medios, pero algún tipo de formato que se ocupe de seleccionar lo más interesante, contextualizarlo, hacerlo 
comprensible y ordenarlo es imprescindible, porque si no la sociedad no estará sobre informada, sino narcotizada por una sobredosis de información en la que estará mezclado lo bueno, lo malo, lo fragmentario, lo completo, lo intencionado y lo no intencionado, todo en un chorreo imposible de descifrar" (Gabilondo, 2011).

El primer paso para llevar a cabo la transición será enfrentarse a la idea de que las noticias se están convirtiendo en un producto masificado. Alfonso Bauluz considera que la asimilación de la información "formará parte de las enseñanzas primarias o secundarias de la sociedad" (2013), mientras que para Ángeles Espinosa el reto para las nuevas generaciones será el de discernir lo veraz de lo que no lo es: "sin duda existe el riesgo de que la gente menos preparada ponga al mismo nivel el comentario de un desconocido en un foro de Internet, que el de un intelectual en la Web de un medio a los que ahora se denomina de forma casi despectiva convencional o mainstream" (2013).

Pero quizás el más positivo sea Enric González vaticinando: "estamos en un momento espantoso que es prólogo de un momento muy bueno para el periodismo. Las empresas y los profesionales idiotas se van a quedar encallados aquí, en esta sensación de que ya no hay espacio de periodismo de calidad, pero es algo falso. Las tecnologías proporcionan tal cantidad de buen material para hacer buenas historias que va a ayudar al trabajo del periodista y cuanta más resaca de datos que circula por las redes, más se necesita el periodismo bueno (...). El que se quede en terreno de nadie, ni en el inmediato gratuito ni en el de calidad de pago, va a desaparecer, porque ya están desapareciendo" (2014).

\section{Conclusiones}

Durante todo el proceso hemos podido comprobar que hay diferencia de opiniones entre los corresponsales sobre alguno de los efectos que hemos detectado, pensamos que una de las posibles causas es porque nos encontramos en medio del proceso. Vivimos un periodo de cambio, en el que no sólo han cambiado las tecnologías y la forma de trabajo sino también los modelos informativos. Nuevos medios han dado lugar a nuevos procesos, que todavía están evolucionando, por lo que quizás las respuestas a toda esta transformación se obtengan con mayor claridad en un futuro indeterminado.

Pero a pesar de no poder responder rotundamente a algunas de las incógnitas planteadas, sí podemos llegar a las siguientes conclusiones:

La evolución tecnológica ha ocasionado un ahorro de los costes en las coberturas de conflictos. Los sistemas de comunicación se han popularizado y han descendido los precios, nunca fue tan barato comunicarse o transmitir desde un conflicto, gracias a Internet. Pero a pesar de ello, muchos medios han optado por otras opciones incluso más económicas, como la contratación de reporteros freelance para cubrir este tipo de información. Se les paga una cantidad por un encargo o directamente, se les compra el material si les interesa, ahorrándose los costes del viaje, dietas, seguro, etc. De esta forma pueden valorar, tras ver el material, si lo quieren o no, sin generar ningún gasto anticipadamente. 
Otros medios, han optado por eliminar las corresponsalías de conflictos, cubriéndolos con material de las agencias de noticias. Las agencias son consideradas en general por los corresponsales como una fuente de información que les ayuda en muchas ocasiones, porque les dota de una visión más panorámica sobre el conflicto, al contar con un mayor número de periodistas en el sitio que pueden llegar a lugares a los que no llegan los corresponsales. El problema viene cuando las agencias son utilizadas "en contra" del corresponsal, y los jefes de los medios dan más valor a lo que publican éstas que a la información que transmite su propio reportero, llegando incluso a cambiar sus crónicas. Pero la utilización de las mismas imágenes o informaciones por parte de la mayoría de medios provoca la homogeneización de la información.

Todo esto es justificado por los medios de comunicación achacándolo a la situación de crisis que se vive, pero es una realidad que la información internacional ha ido perdiendo peso a lo largo de los años, para dejar paso a otro tipo de información, como la información nacional o la llamada por algunos como, info-entretenimiento, mucho más económica de producir. Los corresponsales se rebelan contra esta percepción, reclamando que una información internacional de calidad tiene interés en el público, desmintiendo lo que muchos editores o directores de medios afirman.

Algunos corresponsales entienden que el error de la prensa fue sacar los diarios digitales gratuitos, sin darle el valor que tenía la información y ahora ven complicado recuperar a ese lector y más si no mejora la calidad para hacer que vuelva a pagar, porque en la actualidad, circula en la red cientos de informaciones, tantas que algunos han evidenciado que hay un exceso de información.

Ante este panorama, muchos de ellos vaticinan la desaparición de la figura del corresponsal de guerra cuando consideran que su papel es más fundamental, ahora más que nunca, para poder discernir lo veraz de lo que no lo es, afirmando que es uno de los grandes retos a los que nos enfrentamos.

Tras la recopilación y posterior análisis de los testimonios de los corresponsales entrevistados y de la bibliografía específica, hemos podido componer un panorama que da respuesta a nuestra pregunta de investigación, ¿̨cuál es la situación de las corresponsalías de guerra y la información internacional dentro de los medios en España? Hemos podido comprobar cómo los medios cada vez dedican menos tiempo y presupuesto a cubrir los conflictos y la información internacional, sustituyéndola por otra información más barata o local. Se ha sustituido la figura de los corresponsales de guerra, por freelance, que no cuentan con los medios suficientes muchas veces para hacer una cobertura en condiciones, por las agencias de prensa que monopolizan la información, homogeneizándola o, algo más pernicioso, con la información aparecida por fuentes, muchas veces sin contrastar, en Internet o redes sociales. Todo esto hace prever que puede llegar a desaparecer la figura del corresponsal de guerra, algo que dependerá de si los medios de comunicación continúan con esta tendencia. 


\section{Referencias bibliográficas}

Altares, G. (2010): “La química de un oficio sin dioses”, en Martín, A. (eds.): Seguiremos informando. Madrid: deBolsillo, pp. $37-46$.

Briggs, A., y Burke, P. (2002): De Gutemberg a Internet. Madrid: Taurus.

Calaf, R. M. (2008): “El diseño de la información internacional”, en Jurado, M. y Carvajal, M. (eds.): La arquitectura de la información. ¿Quién construye la agenda? Murcia: DM, pp. 97-113.

Cazorla, B. (2009): Fotoperiodismo en la UVI. Disponible en www.elpais.es: http://elpais.com/diario/2009/09/01/cultura/1251756007_850215.html [Consultado 12/05/2013].

Celis, B. (2008): “Nuevos perfiles profesionales para un nuevo periodismo que ya está aquí", Cuadernos de periodistas, pp. 53-58.

Fernández, M. y Marcos, J. (2009): “África, la gran olvidada de los medios españoles”, Cuadernos de periodistas, pp. 89-100. Gabilondo, I. (2011): El fin de una época. Barcelona: Barril Barral.

García de Diego, A., Parra, D. y Rojo, P. A. (2007): Nuevas tecnologías para la producción periodística. Madrid: Siranda.

Kapuściński, R. (2001): “El mundo reflejado en los medios”, en Leguineche, M. y Sánchez, G. (eds.): Los ojos de la guerra. Madrid: Random House Mondadori, pp. 404-417.

- (2002): Los cínicos no sirven para este oficio. Sobre el buen periodismo. Barcelona: Anagrama.

Lavín, E. (2014): “El periodismo ciudadano: una herramienta para las televisiones norteamericanas", en Gallardo, J. y Vadillo, N. (eds.): Las nuevas tecnologías audiovisuales frente a los procesos tradicionales de comunicación. La Laguna (Tenerife): Sociedad Latina de Comunicación Social, pp. 77-90.

Lobo, R. (1999): El héroe inexistente. Los viajes de un corresponsal de guerra al corazón de las tinieblas del fin de siglo. Madrid: Satillana.

Majó, J. (1997): Chips, cables y poder. Barcelona: Planeta.

Miller, R. (2001): “Testigos de otro tiempo”, en Leguineche, M. y Sánchez, G. (eds.): Los ojos de la guerra. Madrid: Random House Mondadori, pp. 489-498.

Pavlik, J. V. (2005): El periodismo y los nuevos medios de comunicación. Barcelona: Paidós Ibérica.

Redacción Prnoticias (2011): El diario ABC sólo quiere colaboradores en su plantilla. Disponible en: http://www.prnoticias.com/index.php/prensa/206-ABC\%20/10067628-los-corresponsales-son-el-principio-abc-quiere-solo-colaboradores [Consultado 1/03/2014].

Rodríguez, N. (2009): “La batalla perdida”, Cuadernos de periodistas, pp. 9-18. 
Salvat Martinrey, G., y Paniagua Santamaría, P. (2007): "¿Es esto periodismo, ciudadano?", Estudios sobre el Mensaje Periodístico, n. 13, pp. 227-246.

Sánchez, G. (2001): “Guerras, mentiras y juegos de vídeo”, en Leguineche, M. y Sánchez, G. (eds.): Los ojos de la guerra. Madrid: Random House Mondadori, pp. 461-472.

Valentín, J. P. (2007): “Las amenazas de los informativos de televisión”, Cuadernos de periodistas, pp. 64-69.

Varela, S. J. (2013): Contra la crisis del fotoperiodismo: foto usada, foto pagada y firmada. Disponible en www.apmadrid.es: http://www.apmadrid.es/noticias/generales/contra-la-crisis-del-fotoperiodismo-foto-usada-foto-pagada-y-firmada [Consultado 21/05/2014]. 